OCCASIONAL REVIEW

\title{
Home oxygen for children: who, how and when?
}

\author{
I M Balfour-Lynn, R A Primhak, B N J Shaw
}

Thorax 2005;60:76-81. doi: 10.1136/thx.2004.031211

\section{A review of the specific requirements of home oxygen therapy in children which attempts to offer guidance to clinicians and service providers}

- Many children require LTOT overnight only, especially during the weaning stages; this is less than the 15 hours that forms part of the adult LTOT definition.

- All children require supervision from a parent/ carer.

- Provision of oxygen may be necessary at school for school age children.

\section{LONG TERM OXYGEN THERAPY (LTOT)}

LTOT refers to the provision of oxygen therapy for continuous use at home for patients with chronic hypoxaemia (due to any cause) in order to maintain oxygen saturation $\left(\mathrm{SaO}_{2}\right)$ at or above $92 \%$ (depending on the type of oximeter) or arterial oxygen tension $\left(\mathrm{PaO}_{2}\right)$ above $8 \mathrm{kPa}$ (see below). It may be required 24 hours a day or during periods of sleep only. Any child likely to require continuous or intermittent oxygen therapy for more than 2-3 weeks should be considered for discharge home on LTOT. The principal aims of LTOT are to prevent harm from chronic hypoxaemia and to improve any relevant symptoms. It is important to be clear about the aims for an individual child as this will affect decisions about target oxygenation (hence titration and weaning of flow rates). London Working Group in 1992 and, although the main document is no longer available, the summary can still be obtained. ${ }^{3}$ The revised 1999 report from the Royal College of Physicians ${ }^{4}$ included a paediatric section, and much of this review is based on that, together with relevant updates. Unfortunately, there is a lack of randomised controlled trial evidence to inform much of the debate.

\section{PRINCIPAL DIFFERENCES FROM TREATMENT OF ADULTS}

These can be summarised as follows:

- Most of the clinical conditions in the infant age group are exclusive and are not seen in adults, although sometimes there is an overlap between older children and young adults.

See end of article for authors' affiliations

.....................

Correspondence to:

Dr I M Balfour-Lynn,

Department of Paediatric

Respiratory Medicine,

Royal Brompton Hospital,

Sydney Street, London

SW3 6NP, UK;

i.balfourlynn@

imperial.co.uk

Received 6 July 2004

Accepted

4 November 2004

- The prognosis in infancy is usually good; many children only need oxygen for a limited period, although this may be for some years.

- Growth and neurodevelopment are important considerations.

- Assessment is different, particularly with regard to the difficulty of arterial blood sampling.

- Specific equipment is required to allow for low oxygen flows.

- Almost all children receiving long term oxygen therapy (LTOT) also require ambulatory oxygen therapy.

\section{Principal paediatric conditions requiring LTOT}

The principal associated conditions in children requiring LTOT are shown in box 1 . The list is not exhaustive and there are a number of other rare causes of chronic hypoxaemia.

Chronic neonatal lung disease

Chronic neonatal lung disease (CNLD) is the main indication for LTOT in children. The term bronchopulmonary dysplasia (BPD) has come to signify the need for supplemental oxygen at various postnatal or postmenstrual ages, and the definition has changed with time. A recent study of almost 1000 babies born weighing $<1000 \mathrm{~g}$ showed that, although the accuracy was limited, use of supplemental oxygen at 36 weeks postmenstrual age was best at predicting long term pulmonary outcome. ${ }^{5}$ Infants with CNLD tend to have been born prematurely and are of very low birth weight. Data from surviving babies born weighing $<1500 \mathrm{~g}$ showed that $19 \%$ developed CNLD. ${ }^{6}$ They often require prolonged assisted ventilation but continue to need supplemental oxygen once extubated. With increased survival of extremely low birthweight premature infants, it is most likely that the incidence of CNLD will also increase, ${ }^{7}$ as will the need for LTOT. It has been suggested that use of supplementary oxygen in CNLD reduces mortality from sudden 
Box 1 Principal paediatric conditions requiring LTOT

- Chronic neonatal lung disease (bronchopulmonary dysplasia)

- Other neonatal lung conditions (e.g. pulmonary hypoplasia)

- Congenital heart disease with pulmonary hypertension

- Pulmonary hypertension secondary to pulmonary disease

- Interstitial lung disease

- Obliterative bronchiolitis

- End stage cystic fibrosis and other causes of severe bronchiectasis

- Obstructive sleep apnoea syndrome and other sleep related disorders

- Neuromuscular conditions requiring non-invasive ventilation

- Disorders of the chest wall (e.g. thoracic dystrophy, severe kyphoscoliosis)

- Palliative care for symptom relief

infant death, ${ }^{8}$ reduces the frequency of intermittent desaturations, ${ }^{8}$ reduces pulmonary hypertension, ${ }^{9}$ reduces reversible obstructive lung disease, ${ }^{10}$ improves growth, ${ }^{11}{ }^{12}$ and is likely to be beneficial for neurodevelopment. ${ }^{13}$ The effect of oxygen on sleep quality is difficult to interpret but it seems that desaturations are reduced, but at the cost of sleep disruption. ${ }^{14-16}$ Although there have been no randomised trials of babies on LTOT, it is suggested that caring for babies on supplementary oxygen at home is preferable to a prolonged hospital stay. ${ }^{17}$ It reduces the risk of nosocomial infection (although friends and relatives who are unwell should stay away) and it is felt that it is good for parent-child bonding. ${ }^{13}$ Finally, it is beneficial in terms of freed resources for neonatal units and reduces the total cost of care for an infant. ${ }^{317} 18$

\section{Other neonatal lung conditions}

Other neonatal lung conditions include pulmonary hypoplasia, congenital pneumonia and meconium aspiration syndrome but, compared with CNLD, these cases are rare. Survivors of congenital diaphragmatic hernia repair not uncommonly develop chronic lung disease, mainly due to pulmonary hypoplasia or lung damage resulting from mechanical ventilation. Some require domiciliary oxygen but this is unusual beyond 2 years of age. ${ }^{19}$

\section{Congenital heart disease (CHD)}

It is likely that only those with pulmonary hypertension (with or without Eisenmenger syndrome) need to be at home on long term oxygen. In cyanotic CHD oxygen has little effect in raising $\mathrm{SaO}_{2}$ and is not indicated, although the degree of polycythaemia may be reduced. ${ }^{20}$ However, in some cases with chronic left to right shunting, irreversible pulmonary vascular disease can develop and cause right to left shunting (Eisenmenger syndrome). In the early stages the resulting pulmonary hypertension may be responsive to oxygen, so this is indicated while the child is waiting for transplantation or for palliation. In a small but important controlled study, $100 \%$ oxygen given for a minimum of 12 hours per day for up to 5 years significantly improved survival in children with pulmonary vascular disease too severe to have corrective surgery. ${ }^{21}$ However, this was not the case in a recent 2 year study of adults with advanced Eisenmenger syndrome where nocturnal oxygen had no impact on survival, exercise capacity, or quality of life. ${ }^{22}$ Some children with CHD who are awaiting corrective surgery (without Eisenmenger syndrome) and who have raised pulmonary artery pressure which is oxygen responsive may benefit from LTOT. Decisions for all these cases are made by specialist paediatric cardiologists.

\section{Pulmonary hypertension}

Pulmonary hypertension resulting from pulmonary disease results from chronic hypoxia and considerably worsens the overall prognosis. ${ }^{23}$ Acute hypoxia causes smooth muscle contraction in pulmonary arteries and sustained hypoxia can cause adaptation of pulmonary endothelium. ${ }^{23}$ LTOT reverses or at least slows the progress of the hypoxic induced changes to the pulmonary vascular bed and can contribute to improved survival. ${ }^{23}$ Primary pulmonary hypertension has a very poor prognosis in children (median survival $<$ l year). Some of the children desaturate during sleep (especially during early morning hours) due to mild hypoventilation which may lead to severe dyspnoea, and the resulting hypoxaemia can be eliminated by supplemental oxygen. ${ }^{20}$ Oxygen must also be available for viral upper respiratory tract infections which may cause some children to desaturate.

\section{Interstitial lung disease}

Interstitial lung disease represents a spectrum of rare conditions (such as chronic pneumonitis of infancy, nonspecific interstitial pnuemonitis, desquamative interstitial pnuemonitis, immunodeficiency) in which oxygen exchange is impaired. Many of the children require LTOT as well as drug therapy and the outlook is variable.

\section{Obliterative bronchiolitis}

Obliterative bronchiolitis leads to severe obstructive lung disease and, while it may occur following a viral infection (e.g. adenovirus), the cause is often unknown. There is no specific treatment; many of the children require LTOT and again the outlook is variable.

\section{Cystic fibrosis (CF)}

As the treatment for CF improves, there are fewer children with CF who require LTOT (estimated to be $1-2 \%$ paediatric CF patients). There is surprisingly little evidence for the benefit of LTOT in CF and, while it led to an improvement in school or work attendance, there was no effect on mortality rate, frequency of hospitalisation, or disease progression. ${ }^{24}$ It is therefore recommended that LTOT is reserved for those CF patients who obtain symptomatic relief. ${ }^{25}$ This is similar to the indications for palliative care where some children feel better for having supplemental oxygen. There are other causes of bronchiectasis in children (although in approximately $50 \%$ cases no underlying cause is found), and occasionally LTOT is necessary for those with severe disease.

\section{Obstructive sleep apnoea syndrome}

Obstructive sleep apnoea syndrome (OSAS) may require noninvasive ventilation (NIV) if the obstruction cannot be relieved. Occasionally supplemental oxygen alone is used if the child does not tolerate the facemask ventilation-for example, some children with Down's syndrome. Oxygen does not suppress the ventilatory drive in the majority of children with OSAS but $\mathrm{PaCO}_{2}$ should be monitored. ${ }^{26}$ It is important that children with sickle cell disease and upper airway obstruction do not become hypoxaemic as it can lead to debilitating episodes of sickling. ${ }^{27}$ As the incidence of childhood obesity continues to increase, OSAS is likely to become a more frequent problem. 


\section{Chronic hypoventilation}

There are a number of patients who require long term NIV because of chronic hypoventilation (to control hypercapnia as well as hypoxaemia). Oxygen alone is inadequate for most children with chronic hypoventilation. A UK survey in 1997 estimated the number of children receiving NIV to be 141 of which 93 (65\%) were at home. ${ }^{28}$ The incidence was shown to have increased over the previous decade and it is likely that this will continue to increase in the future. The children had a variety of conditions, principally neuromuscular disorders $(46 \%)$, congenital central hypoventilation syndrome (13\%), spinal injury (12\%), craniofacial syndromes $(7 \%)$, and bronchopulmonary dysplasia $(4 \%)$. There were a number of other less frequent causes (18\%). In $35 \%$ of cases they had access to supplemental oxygen at home as well (E Jardine, personal communication). Core guidelines have suggested that children on home ventilation should have a stable oxygen requirement with an $\mathrm{FiO}_{2}$ of usually less than $40 \% .{ }^{29}$

\section{Assessment in infancy}

Suitability for domiciliary oxygen therapy should be assessed by a specialist with appropriate experience in the care of the relevant condition; this is usually either a respiratory paediatrician or a neonatologist (but may be a paediatric cardiologist, general paediatrician or palliative care specialist). The family must also be assessed for their competence to manage home oxygen therapy and be able to cope with all aspects of the baby's care.

In adults the measurement of arterial $\mathrm{PaO}_{2}$ is considered critical, but this is not always possible or practical in infants. In paediatric practice, oxygen saturation measured by pulse oximetry remains the main form of assessment, as results of an arterial stab from a crying (hypoxic) child is unreliable, whilst capillary $\mathrm{PaO}_{2}$ does not necessarily correlate with arterial $\mathrm{PaO}_{2}{ }^{30}{ }^{30}$ One-off measurements are insufficient and, before discharge, saturations must be measured continuously for at least 6-12 hours to include periods of sleep, wakefulness and activity/feeding. It is important to include these periods as infants have an increased oxygen requirement during activity and infants with CNLD may develop feeding related hypoxaemia. ${ }^{31}$ In addition, some children may only show evidence of nocturnal hypoxaemia without daytime hypoxaemia. An instrument should be used that has been validated in infants and it has been suggested that pulse oximeter readings should be verified by an arterial gas measurement at the start of the study; however, this is usually impractical in children and we do not feel it is essential. It must still be remembered, however, that correlation between $\mathrm{SaO}_{2}$ and arterial $\mathrm{PaO}_{2}$ is such that, at 94\% saturation, the $\mathrm{PaO}_{2}$ may vary from 9 to $17 \mathrm{kPa}{ }^{32}$ Although correlation is particularly poor in the saturation range of $85-90 \%$, ${ }^{33}$ this is not critical as all infants with $\mathrm{SaO}_{2}$ $<90 \%$ should receive LTOT anyway.

Most of the work in infancy relates to CNLD and there is only limited evidence to recommend a minimally acceptable level of oxygenation. The normal $\mathrm{SaO}_{2}$ is around $96 \%$ and supplemental oxygen should be considered for infants who cannot maintain $\mathrm{SaO}_{2}$ at $93 \%$ or above when asleep or quietly awake. ${ }^{8}$ Oxygen therapy should be given to achieve an $\mathrm{SaO}_{2}$ above $92 \%$ and recommendations have suggested keeping it at $95 \%$ or above. ${ }^{8}$ However, a recent randomised controlled study (the "BOOST" trial) in 358 premature infants still requiring oxygen at 32 weeks postmenstrual age showed that maintaining $\mathrm{SaO}_{2}$ at $95-98 \%$ had no advantage over 91-94\% in terms of growth and neurodevelopment assessed at 1 year of age (using N-3000 Nellcor oximeters). ${ }^{34}$ The study also found that the group with the higher target oxygen level had an excess of deaths from pulmonary causes, albeit not statistically significant. This is in keeping with another study (the "STOP-ROP" trial on retinopathy of prematurity) in which 649 preterm infants were randomly assigned to different target oxygen levels (89-94\% $v 96-99 \%$ ) for at least 2 weeks. $^{35}$ They used Ohmeda 3470 oximeters that are calibrated to display an $\mathrm{SaO}_{2}$ which is lower by $1.6 \%$ saturation points than other commercial oximeters. They found an increased rate of adverse pulmonary sequelae (pneumonia and exacerbations of CNLD), although not deaths, in the high saturation group when assessed at 3 months after the due date of the infant (13.2\% v 8.5\%). The high saturation group also had more infants still requiring supplemental oxygen at 3 months (47\% v 37\%). Oxygen toxicity, particularly in premature infants, can inhibit lung healing and contribute to ongoing lung injury, ${ }^{36}$ so it would seem that treatment should aim to keep $\mathrm{SaO}_{2}$ at $92-94 \%$ in infants, particularly during the preterm period, with no more than $5 \%$ of time spent below $90 \%$ saturation.

\section{Assessment in older children}

In older children adult criteria for oxygen prescription may be acceptable, although specific studies on upper and lower limits of $\mathrm{PaO}_{2}$ for LTOT are lacking. It is important to include an entire night (with at least 4 hours uninterrupted sleep) in case the child only develops nocturnal hypoxaemia. Data for normal overnight $\mathrm{SaO}_{2}$ measured by pulse oximetry are available and a recent study in primary school children (mean age 9.3 years) showed that the average $\mathrm{SaO}_{2}$ was approximately $98 \%$ and baseline $\mathrm{SaO}_{2}<97 \%$ was uncommon. ${ }^{37}$ Furthermore, while intermittent desaturations by $4 \%$ or more were frequent, the $\mathrm{SaO}_{2}$ rarely fell to $90 \%$ or below. Overnight assessment is important as nocturnal hypoxaemia usually precedes daytime desaturation in children with CF. In children with hypoventilation, such as in neuromuscular disease, it is important to check the carbon dioxide status as, in the presence of hypercapnia, NIV will be necessary rather than LTOT alone. Measurement of overnight transcutaneous or end tidal $\mathrm{CO}_{2}$ is ideal, although a capillary $\mathrm{CO}_{2}$ taken just as the child wakes up may be useful if the former are not available. Full polysomnography is not usually required.

\section{Discharge criteria}

A multidisciplinary meeting should ensure discharge planning is achieved properly. Extensive collaboration is required between the parents and multidisciplinary team, and in some cases it may be appropriate to include a representative of the service contractor in discharge planning to ensure carers are comfortable with the arrangements. The goal is to select the infants and families most likely to cope at home and to get the timing of discharge right. ${ }^{38}$

- Oxygen requirement must be stable with mean $\mathrm{SaO}_{2}$ of 93\% or above, without frequent episodes of desaturation. The $\mathrm{SaO}_{2}$ should not fall below $90 \%$ for more than $5 \%$ of the artefact-free recording period.

- Babies should be able to cope with short periods in air without being at risk of rapid deterioration in case their nasal cannulae become dislodged. Generally this will apply to those requiring $<0.5 \mathrm{l} / \mathrm{min}$, but this does not mean that some babies with a higher oxygen requirement cannot be on home oxygen.

- No other clinical conditions precluding discharge are present, and the child is medically stable with satisfactory growth. No apnoeic episodes for at least 2 weeks.

- Immunisations up to date. Palivizumab (Synagis) may be considered at the appropriate time of year for infants with CNLD requiring home oxygen.

- Parents are willing and felt to be capable of taking the baby home while still on oxygen. 
- Home conditions must be satisfactory and preferably a telephone should be installed (or use of a mobile phone available). A visit from a member of the home care team is required before discharge.

- Parents are trained and have written information on the use of home oxygen and also cardiopulmonary resuscitation in the case of infants. Vigilance for an empty oxygen supply, dislodged cannulae, or blocked valve is critical. A structured education programme can be useful. ${ }^{39}$

- Advice should be given about no smoking in the home; it needs to be strongly discouraged but help to do so must be offered.

- Advice must also be given about open flames (such as birthday cake candles) ${ }^{40}$

- Older children also need to have training on how to use their oxygen equipment.

- Parents must be advised about travel with cylinders and inform their home and car insurers.

- Appropriate support must be in place-for example, community nursing, nurse specialists, health visitor, social workers.

- Communication with general practitioner has taken place and roles have been clarified for delivering clinical care.

- Parents must have a list of telephone numbers for advice and emergency help including equipment breakdown.

- Arrangements are in place for open access to the local paediatric unit.

\section{Equipment}

Much of the information on LTOT equipment for adults applies to children, but there are some specific issues:

- Oxygen concentrators are usually the preferred devices with back up cylinders for breakdown and portable cylinders (preferably lightweight) for ambulatory use.

- Oxygen concentrators need two outlets, one in the child's bedroom and one in the main living room area.

- Oxygen cylinders may be more appropriate if initial flow rates are lower than $0.3 \mathrm{l} / \mathrm{min}$ and the anticipated duration of oxygen therapy is less than 3 months. A back up cylinder must be available for those on continuous oxygen. Particular attention must be paid to safety and securing of cylinders in the presence of young children.

- Low flow meter (0.1-1 l/min) must be available for infants and very young children.

- Humidification system is often required for those on flow rates above $1 \mathrm{l} / \mathrm{min}$ for nasal comfort. Cold bubble humidifiers may be used for this purpose, but they only achieve $40 \%$ relative humidity and are inadequate for direct airway humidification (for example, via a tracheostomy). Heated humidification is less convenient for domestic use and is only effective at flow rates of $4 \mathrm{l} /$ min or higher delivered by a concentrator as water can block the tubing at lower flow rates.

- Appropriately sized soft twin prong nasal cannulae (small children rarely tolerate $>2 \mathrm{l} / \mathrm{min}$ by nasal cannulae), facemask, and non-kinking extension tubing must be provided by the hospital. Stomahesive (or equivalent) should also be provided to protect the skin in those using nasal cannulae.

- Ambulatory equipment must be available as part of the oxygen delivery systems unless oxygen is only required at night. This must be lightweight so that older children can handle it themselves, and for infants it must fit on to a pram/pushchair. Parents need advice on the type of pram to buy-for example, one with a metal basket underneath that is safe and strong enough to hold the cylinder.

- Children in wheelchairs need to have a cylinder fitting provided by their wheelchair service to maintain safety.

\section{Oxygen saturation monitor (pulse oximeter)}

The issue of whether parents should be provided with their own saturation monitor has been an area of debate. If a child requires continuous monitoring then it is unlikely they are ready for hospital discharge. There is no evidence that provision of oximeters improves the outcome of babies on home oxygen, and in practice may lead to excessive adjustments of the flow rate by the carers. ${ }^{41}$ It may give false reassurance, and oxygen saturation is only one aspect of the baby's respiratory status. Some parents, however, request one for spot measurements as a guide to when oxygen needs increasing-for example, when the baby has a cold. Our recommendation would be that the baby should be seen in these circumstances, usually by the home care nurse who can then make a full assessment. The use as an overnight "alarm" is unsatisfactory because of the number of false alarms, mostly from movement artefact. The American Thoracic Society has supported provision of oximeters to parents, but their rationale seems to be mostly cost based in terms of reducing hospital and office visits. ${ }^{42}$

\section{Patient follow up arrangements}

Arrangements for follow up after discharge should be coordinated by the hospital specialist who has initiated domiciliary oxygen. Liaison must take place between the specialist (usually a respiratory paediatrician or neonatologist), local and/or community paediatrician, general practitioner, nurse specialists (usually based in tertiary respiratory or neonatal units), community paediatric nursing service, occupational therapist, and health visitor. A study in Oxford on 55 babies with CNLD at home with LTOT looked at healthcare use in 31 of the babies. ${ }^{17}$ They found that they received a median of 43 visits per baby (range 8-173) from a paediatric community nurse, and these lasted a median of 45 minutes; $83 \%$ saw a health visitor with a median of 12 visits (range 2-82) and they were for a median of 30 minutes; $83 \%$ saw a GP with a median of 6 visits (range 1-140) and they were for a median of 10 minutes. A lesser proportion also saw a hospital consultant (they almost all had hospital clinic visits, however, on a median four occasions), social worker, physiotherapist and speech therapist.

The oxygen requirement is likely to change with time and, in the case of infants with CNLD, it should gradually reduce. Regular home monitoring using pulse oximetry is necessary and should be set up by community/specialist nurses. A visit within the first 24 hours is important to allay parental anxiety. The first formal saturation monitoring should take place within a week; subsequent recordings should occur as clinically indicated, but rarely less often than every 3-4 weeks. ${ }^{41}$ Recorded data can then be discussed with the supervising consultant although protocols can be in place for experienced nursing teams to initiate changes. The length of time infants with CNLD remain on LTOT varies but is usually 6-12 months, although some require it for several years.

Infants with CNLD who require home oxygen have more frequent and longer hospital admissions and more clinic attendances than those sent home without oxygen. ${ }^{43}$ This is particularly the case if they had been hospitalised in the first 2 years of life with RSV infection, which had a significant impact on cost of care. ${ }^{44}$ In the Oxford study $41 \%$ of the babies required readmission on a median of 1 occasion (range $0-10$ ), staying for a median 9 days (range 1-64). ${ }^{17}$ The children should be seen regularly by the hospital specialist in 
clinic in order to monitor the underlying condition as well as growth and neurodevelopment. There must be direct access for the child to be admitted to hospital in the case of any emergency or acute deterioration in the condition, and the parents must have the telephone numbers of the team. Even a simple viral upper respiratory tract infection in a young infant on LTOT may necessitate admission, and winter (particularly the first) can be an anxious time for parents. If the carers believe the child requires an increase in oxygen, they can turn up the flow rate but must then seek advice from the home care team.

It is recommended that influenza immunisation should be given to children with chronic respiratory disease requiring home oxygen, although the vaccine is not licensed for those aged under 6 months. In these cases it is worthwhile immunising household contacts and other caregivers to give some protection to the child. ${ }^{45}$

Even when the child comes off oxygen, support must continue as children may sometimes relapse and require further periods of oxygen therapy after an apparently complete recovery. This is usually related to intercurrent infection.

\section{Weaning off LTOT}

The issue of weaning off oxygen principally applies to infants with CNLD and some other neonatal lung conditions. In children with congenital heart disease, only those having successful corrective surgery or transplantation will no longer require LTOT. Some young children with interstitial lung disease or obliterative bronchiolitis may improve sufficiently to lose their oxygen dependency. Older children with progressive lung disease such as CF or neuromuscular conditions usually continue to require oxygen for the remainder of their lives. It is not easy to counsel parents as to how long LTOT will be needed. Although capillary blood $\mathrm{PaCO}_{2}$ measured near term correlated with length of oxygen dependency for a group of babies with CNLD, it was impossible to predict for an individual ${ }^{46}$ However, in general those with a higher $\mathrm{PaCO}_{2}$ are more likely to require oxygen for longer. The length of time infants with CNLD remain on LTOT varies but is usually under 12 months, although some require it for a number of years. ${ }^{47-49}$ Persisting symptoms or failure to progress warrant review to rule out conditions such as tracheobronchomalacia, large airway stenosis or granuloma formation, gastro-oesophageal reflux, recurrent aspiration, or unsuspected congenital cardiac disease.

There is an enormous variety of practice with regard to the criteria used by paediatricians as to when to discontinue LTOT in children with CNLD which reflects the lack of evidence on which to base guidelines. ${ }^{2}$ Regular reassessment (usually monthly if the child is stable) in the home using a pulse oximeter with a data recording facility is necessary. During periods of weaning or withdrawal of oxygen, more frequent monitoring will be needed. It is not normally necessary for the child to have an oxygen saturation monitor kept in the home as one can be provided for intermittent monitoring. Recording should include daytime activity, feeding and sleep. Short term awake $\mathrm{SaO}_{2}$ measurements do not predict prolonged sleeping $\mathrm{SaO}_{2} \cdot{ }^{50}$ The same target saturations used to decide supplementation are used for weaning purposes (92-94\%). Saturation targets in the physiological range (95-98\%) may be felt to be desirable in infants with pulmonary hypertension. In a study using 2 hour room air challenges, most infants reached their lowest saturations within 40 minutes of discontinuing oxygen and a level of $92 \%$ or above best predicted readiness for weaning judged by 6 month follow up. ${ }^{51}$ Furthermore, infants requiring an oxygen flow rate of $0.02 \mathrm{l} / \mathrm{kg} / \mathrm{min}$ were most likely to be successfully weaned. ${ }^{51}$
Some units wean infants from continuous low flow oxygen to night time and naps only while others maintain continuous oxygen until the child has no requirement at all; there is no evidence to recommend which approach is best. When the oxygen requirement is minimal, the children should have supervised weaning into air with continuous monitoring (that will include active periods and sleep). Babies tend to be weaned down to an oxygen flow rate of $0.1 \mathrm{l} / \mathrm{min}$ using a low flow meter, and from that level they can usually be weaned straight to air. Although very (or ultra) low flow meters exist $(0.025-0.2 \mathrm{l} / \mathrm{min})$ so that in theory the flow can be reduced further before weaning to air, it is usually unnecessary and, in addition, there is a concern that some carers may become confused by the decimal points. Weaning is preferably done at home as it minimises the chances of nosocomial infection, although a brief hospital admission may sometimes be needed. It is usually prudent to ensure that the child has coped with at least one viral upper respiratory tract infection without problems before the equipment is removed from the home, and it should be left there for a few months, especially in the winter.

\section{AMBULATORY OXYGEN THERAPY}

All children on LTOT require facilities for portable ambulatory oxygen therapy unless they only use night time oxygen. This particularly applies to the infant age group (who spend periods in the day sleeping) as parents will need to be able to take the baby out of the home in order to lead as normal a life as possible. It is essential that appropriate equipment is available-for example, oxygen cylinders that fit on a pram. The duration of ambulatory oxygen therapy will usually increase with older children who are rarely "house bound", but a separate source should be provided at school.

\section{OXYGEN IN SCHOOLS}

There is a small but important demand for oxygen therapy to be available in schools. Liaison is required between the specialist paediatric respiratory team and the education health services, and this is usually coordinated by community paediatric services. The following need particular consideration:

- Oxygen delivery equipment must be lightweight and easy for the child to handle and adjust.

- Safety devices must be in place for stabilising oxygen cylinders or other equipment.

- Insurance cover must be obtained by the school for staff and premises.

- Adequate technical back up must be available.

- School staff must be trained in the use of oxygen therapy.

- School staff must have easily identified healthcare contacts.

- Provision must be made for ambulatory oxygen for the journey to and from school.

\section{SHORT BURST OXYGEN THERAPY}

There are no indications specific to children. In any case, they should be supervised in hospital if they require acute use of short term oxygen-for example, during severe acute asthma.

\section{CONCLUSIONS}

The home oxygen service is undergoing a huge change and, by integrating the service, there should be improvements for both prescribers and users. Clearly there are far fewer children than adults requiring home oxygen but their needs are quite different. Fortunately this is being taken into account during the planning stages. The new service should 
also present opportunities for research/audit and redefining guidelines.

\section{ACKNOWLEDGEMENTS}

The authors thank Beverly Hicks (occupational therapist, Royal Brompton Hospital) and Alison Bedford-Russell (consultant neonatologist, Chelsea and Westminster Hospital) for advice over aspects of this document.

\section{Authors' affiliations}

I M Balfour-Lynn, Department of Paediatric Respiratory Medicine, Royal Brompton Hospital, London, UK

R A Primhak, University Department of Child Health, Sheffield Children's Hospital, Sheffield, UK

B N J Shaw, Department of Respiratory and Neonatal Paediatrics, Liverpool Women's Hospital, Liverpool, UK

The authors are members of the British Thoracic Society Home Oxygen Working Party. There is no conflict of interest.

\section{REFERENCES}

1 Ellsbury DL, Acarregui MJ, McGuinness GA, et al. Controversy surrounding the use of home oxygen for premature infants with bronchopulmonary dysplasia. J Perinatol 2004;24:36-40.

2 Solis A, Harrison G, Shaw BN. Assessing oxygen requirement after discharge in chronic lung disease: a survey of current practice. Eur J Pediatr 2002;161:428-30.

3 Silverman M. Domiciliary oxygen therapy for children. Summary of a report of a Working Group of the Committee on Thoracic Medicine of the Royal College of Physicians. J R Coll Physicians Lond 1992;26:125-7.

4 Royal College of Physicians. Domiciliary oxygen therapy services. Clinical guidelines and advice for prescribers. Report of a Working Party of the Royal College of Physicians, London, 1999.

5 Davis PG, Thorpe K, Roberts R, et al. Evaluating "old" definitions for the "new" bronchopulmonary dysplasia. J Pediatr 2002; 140:555-60.

6 Stevenson DK, Wright LL, Lemons JA, et al. Very low birth weight outcomes of the National Institute of Child Health and Human Development Neonatal Research Network, January 1993 through December 1994. Am J Obstet Gynecol 1998;179:1632-9.

7 Hack M, Fanaroff AA. Outcomes of children of extremely low birthweight and gestational age in the 1990s. Semin Neonatol 2000;5:89-106.

8 Poets CF. When do infants need additional inspired oxygen? A review of the current literature. Pediatr Pulmonol 1998;26:424-8

9 Abman SH, Wolfe RR, Accurso FJ, et al. Pulmonary vascular response to oxygen in infants with severe bronchopulmonary dysplasia. Pediatrics 1985;75:80-4.

10 Tay-Uyboco JS, Kwiatkowski K, Cates DB, et al. Hypoxic airway constriction in infants of very low birth weight recovering from moderate to severe bronchopulmonary dysplasia. J Pediatr 1989;115:456-9.

11 Groothuis JR, Rosenberg AA. Home oxygen promotes weight gain in infants with bronchopulmonary dysplasia. Am J Dis Child 1987;141:992-5.

12 Hudak BB, Allen MC, Hudak ML, et al. Home oxygen therapy for chronic lung disease in extremely low-birth-weight infants. Am J Dis Child 1989; 143:357-60

13 Kotecha S, Allen J. Oxygen therapy for infants with chronic lung disease. Arch Dis Child Fetal Neonatal Ed 2002;87:F1 1-4.

14 Harris MA, Sullivan CE. Sleep pattern and supplementary oxygen requirements in infants with chronic neonatal lung disease. Lancet 1995;345:831-2.

15 Fitzgerald D, Van Asperen P, Leslie G, et al. Higher $\mathrm{SaO}_{2}$ in chronic neonatal lung disease: does it improve sleep? Pediatr Pulmonol 1998;26:235-40.

16 Simakajornboon N, Beckerman RC, Mack C, et al. Effect of supplemental oxygen on sleep architecture and cardiorespiratory events in preterm infants. Pediatrics 2002;110:884-8.

17 Hallam L, Rudbeck B, Bradley M. Resource use and costs of caring for oxygendependent children: a comparison of hospital and home-based care. J Neonatal Nursing 1996;2:25-30.

18 Greenough A, Alexander J, Burgess S, et al. High versus restricted use of home oxygen therapy, health care utilisation and the cost of care in chronic lung disease. Eur J Pediatr 2004;163:292-6.

19 Jaillard SM, Pierrat V, Dubois A, et al. Outcome at 2 years of infants with congenital diaphragmatic hernia: a population-based study. Ann Thorac Surg 2003;75:250-6

20 Widlitz A, Barst RJ. Pulmonary arterial hypertension in children. Eur Respir J 2003;21:155-76.
21 Bowyer JJ, Busst CM, Denison DM, et al. Effect of long term oxygen treatment at home in children with pulmonary vascular disease. Br Heart $J$ 1986;55:385-90

22 Sandoval J, Aguirre JS, Pulido T, et al. Nocturnal oxygen therapy in patients with Eisenmenger syndrome. Am J Respir Crit Care Med 2001;164:1682-7.

23 Higenbottam T, Cremona G. Acute and chronic hypoxic pulmonary hypertension. Eur Respir J 1993;6:1207-12.

24 Zinman $\mathbf{R}$, Corey $M$, Coates $A L$, et al. Nocturnal home oxygen in the treatment of hypxemic cystic fibrosis patients. J Pediatr 1989;1 14:368-77.

25 Schidlow DV, Taussig LM, Knowles MR. Cystic Fibrosis Foundation consensus conference report on pulmonary complications of cystic fibrosis. Pediatr Pulmonol 1993;15:187-98.

26 Marcus CL, Carroll JL, Bamford O, et al. Supplemental oxygen during sleep in children with sleep-disordered breathing. Am J Respir Crit Care Med 1995;152:1297-301

27 Blaisdell CJ. Sickle cell disease and breathing during sleep. Lung Biology in Health and Disease 2000;147:755-63.

28 Jardine $E$, $O^{\prime}$ Toole $M$, Paton JY, et al. Current status of long term ventilation in children in the United Kingdom: questionnaire survey. BMJ 1999;318:295-9.

29 Jardine $\mathbf{E}$, Wallis $\mathrm{C}$. Core guidelines for the discharge home of the child on long term assisted ventilation in children in the United Kingdom. Thorax 1998;53:762-7.

30 Yildizdas D, Yapicioğlu H, Yilmaz HL, et al. Correlation of simultaneously obtained capillary, venous, and arterial blood gases of patients in a paediatric intensive care unit. Arch Dis Child 2004:89:176-80.

31 Singer L, Martin RJ, Hawkins SW, et al. Oxygen desaturation complicates feeding in infants with bronchopulmonary dysplasia after discharge. Pediatrics 1992;90:380-4

32 Wasunna A, Whitelaw AG. Pulse oximetry in preterm infants. Arch Dis Child 1987;62:957-8.

33 Roberts CM, Bugler JR, Melchor R, et al. Value of pulse oximetry in screening for long-term oxygen therapy requirement. Eur Respir J 1993;6:559-62.

34 Askie LM, Henderson-Smart DJ, Irwig L, et al. Oxygen-saturation targets and outcomes in extremely preterm infants. N Engl J Med 2003;349:959-67.

35 Anon. Supplemental Therapeutic Oxygen for Prethreshold Retinopathy Of Prematurity (STOP-ROP), a randomized, controlled trial. I: Primary outcomes, Pediatrics 2000;105:295-310.

36 Weinberger B, Laskin DL, Heck DE, et al. Oxygen toxicity in premature infants. Toxicol Appl Pharmacol 2002;181:60-7.

37 Urschitz MS, Wolff J, Von Einem V, et al. Reference values for nocturnal home pulse oximetry during sleep in primary school children. Chest 2003;123:96-101.

38 Gracey K, Talbot D, Lankford R, et al. The changing face of bronchopulmonary dysplasia: Part 2. Discharging an infant home on oxygen. Adv Neonatal Care 2003:3:88-98.

39 Brown KA, Sauve RS. Evaluation of a caregiver education program: home oxygen therapy for infants. J Obstet Gynecol Neonatal Nurs 1994;23:429-35

40 Laubscher B. Home oxygen therapy: beware of birthday cakes. Arch Dis Child 2003;88:1125.

41 Primhak RA. Discharge and aftercare in chronic lung disease of the newborn. Semin Neonatol 2003;8:117-26.

42 American Thoracic Society. Statement on the care of the child with chronic lung disease of infancy and childhood. Am J Respir Crit Care Med 2003; 168:356-96.

43 Greenough A, Alexander J, Burgess S, et al. Home oxygen status and rehospitalisation and primary care requirements of infants with chronic lung disease. Arch Dis Child 2002:86:40-3.

44 Greenough A, Alexander J, Burgess S, et al. Health care utilisation of prematurely born, preschool children related to hospitalisation for RSV infection. Arch Dis Child 2004;89:673-8.

45 Munoz FM. Influenza virus infection in infancy and early childhood. Paediatr Respir Rev 2003;4:99-104.

46 Victor S, Shaw B. Carbon dioxide levels do not predict duration of home oxygen requirement: a retrospective study. J Perinat Med 2002;30:333-5.

47 Sauve RS, McMillan DD, Mitchell I, et al. Home oxygen therapy. Outcome of infants discharged from NICU on continuous treatment. Clin Pediatr 1989;28:113-8.

48 Baraldi E, Carra S, Vencato F, et al. Home oxygen therapy in infants with bronchopulmonary dysplasia: a prospective study. Eur J Pediatr 1997; 156:878-82.

49 Hazinski TA. Bronchopulmonary dysplasia. In: Chernick V, Boat TF, eds. Kendig's disorders of the respiratory tract in children. Philadelphia: WB Saunders, 2000:364-85.

50 Moyer-Mileur L, Nielson DW, Pfeffer KD, et al. Eliminating sleep-associated hypoxemia improves growth in infants with bronchopulmonary dysplasia. Pediatrics 1996;98:779-83.

51 Simoes EA, Rosenberg AA, King SJ, et al. Room air challenge: prediction for successful weaning of oxygen-dependent infants. J Perinatol 1997;17:125-9. 